Abstract

\title{
Challenges in Wireless System Integration in the Implementation of Smart City Environments ${ }^{+}$
}

\section{Francisco Falcone ${ }^{1,2}$}

1 Electrical and Electronic Engineering Dept., Public University of Navarre, Pamplona, 31006 Pamplona, Spain; francisco.falcone@unavarra.es

2 Institute of Smart Cities, Public University of Navarre, Pamplona, 31006 Pamplona, Spain

+ Presented at the 3rd International Electronic Conference on Sensors and Applications, 15-30 November 2016; Available online: https://sciforum.net/conference/ecsa-3.

Published: 19 October 2016

\begin{abstract}
The advent of Internet of Things and the evolution of wireless communication systems (towards 4G and 5G systems, as well as wireless sensor networks) is leading towards the implementation of context aware environments. The adoption of such scenarios requires intensive effort in order to optimize coverage/capacity relations, reducing interference and hence, providing optimal Quality of Service and minimum energy consumption. In this work, some of these challenges in relation with wireless system integration, as well as Context Aware scenario examples will be described.
\end{abstract}

Keywords: Wireless Systems; Context Aware Scenarios; IoT; CPS

(C) 2016 by the authors. Licensee MDPI, Basel, Switzerland. This article is an open access article distributed under the terms and conditions of the Creative Commons Attribution (CC BY) license (http://creativecommons.org/licenses/by/4.0/). 